\title{
EL DERECHO INTERNACIONAL PÚBLICO DEL MEDIO AMBIENTE AL INICIO DEL SIGLO XXI
}

\section{Víctor Manuel ROJAS AMANDI*}

ResumEn: El Derecho Internacional Público del Medio Ambiente (DIPMA) se ha desarrollado fundamentalmente desde fines de los años sesenta, en especial a partir de la Conferencia de Estocolmo. Respecto de sus fuentes, el autor aborda principalmente los tratados. El autor discute además el contenido del derecho consuetudinario en la materia, que incluye cuestiones sustantivas, procesales y de responsabilidad. El soft law y el papel de las organizaciones internacionales son considerados especialmente importantes en la materia. La retorsión y las represalias son consideradas más adecuadas que las contramedidas para aplicar obligaciones ambientales. La conclusión es que el DIPMA protege en particular la regeneración del medio ambiente, que es considerado un derecho humano. Sin embargo, la protección del ambiente está aún sujeta a prioridades económicas y políticas, ya sean nacionales o internacionales.

ABSTRACT: International Public Environmental Law has developed mainly since the late 1960's, particularly since the Stockholm Conference. Regarding its sources, the author addresses mainly treaties. The author further discusses the content of customary law on the subject, including substantive, procedural and international responsibility issues. Soft law and the role of international organizations are considered particularly relevant regarding environmental law. Retortion and reprisals are considered more adequate means than countermeasuers to implement environmental obligations. The conclusion reached is that modern International Public Environmental Law protects particularly the regeneration of the environment, which is considered to be a human right. However, the protection of the environment is still subject to economic and political priorities, whether national or international.

RESUmÉ: Le Droit International Public de l'Environnement s'est essentiellement développé à partir de la fin des années 60, particulièrement depuis la Conférence de Stockholm. Par rapport à ces sources, l'auteur nous explique les différents Traités signés. L'auteur aborde également le contenu du droit coutumier en la matière, lequel inclus les questions relatives aux aspects substantifs, de procédure et de responsabilité. Le soft law et le rôle des organisations internationales sont considérées comme importants dans la matière. Les mesures de rétorsion et les représailles sont considérés comme plus adaptées que l'institution d'obligations environnementales. La conclusion est que le Droit International Public de l'Environnement protège en particulier la régénération de l'environnement, qu'il est considéré comme un droit de l'homme. Pourtant, la protection de l'environnement se trouve encore assujettie aux priorités économiques et politiques, qu'elles soient nationales ou internationales.

\footnotetext{
* Profesor de tiempo completo del Departamento de Derecho de la Universidad Iberoamericana.
} 
SUMARIO: I. Introducción. II. Desarrollo histórico. III. Fuentes. IV. Organismos internacionales. V. Aplicación de las normas del DIPMA. VI. Características del DIPMA. VII. Conclusiones.

\section{INTRODUCCIÓN}

El Derecho Internacional Público del Medio Ambiente (DIPMA) ${ }^{1}$ es una rama especial del Derecho Internacional Público (DIP) de reciente aparición. ${ }^{2}$ Es a partir del final de la década de los sesenta y principio de la de los setenta del siglo XX, cuando se han comenzado a formar reglas generales y principios especiales mediante los cuales la protección del medio ambiente ha llegado a ser objeto de regulación plena por las normas del DIP. Con anterioridad a dicha época, el DIP sólo regulaba aspectos especiales de lo que hoy se entiende por protección del medio ambiente. ${ }^{3}$

1 Un concepto que defina el DIPMA con base en su materia común de regulación y funciones aún no existe. Lo anterior se debe a que el término medio ambiente no ha podido ser definido ni en el ámbito legal, ni en el nivel de la ciencia. Algunos acuerdos internacionales de la materia definen sólo su ámbito territorial de validez y las medidas que deben ser aplicadas o suprimidas para combatir y prevenir los daños sobre el entorno natural. De esta forma, en el sentido de tales acuerdos, medio ambiente es el elemento natural que constituye el objeto de protección de los mismos. Es comúnmente aceptado que bajo el concepto de medio ambiente se incluya tanto el entorno natural del ser humano, como el creado por el mismo. Se suele reconocer que el medio ambiente natural se integra por el suelo y las aguas — aguas internas y mares - incluyendo los mantos acuíferos, así como los territorios cubiertos por hielo permanentemente; el aire junto con la atmósfera, incluyendo el clima; el mundo y los demás componentes del universo y la flora y fauna. En el concepto de medio ambiente creado por el hombre se incluyen entre otros a los bosques, lagos, paisajes, vías de comunicación, ciudades, etcétera. El DIPMA se integra por aquellas normas del DIP que tienen por objeto la protección de los elementos del medio ambiente. Dentro de tal definición se incluyen no solamente las normas de los tratados y costumbres internacionales, sino también aquellas normas no obligatorias a las que se conoce como soft law, tales como las declaraciones de Estocolmo y de Río de Janeiro, las recomendaciones de la OECD o del Programa de Medio Ambiente de Naciones Unidas (PNUMA). El DIPMA no es una materia sistemática, cerrada, excluyente y perfectamente delimitada, sino que por el contrario, tiene un carácter más pragmático que describe un objeto de regulación central y sus normas aparecen tanto en regulaciones internacionales especiales, como en otras de naturaleza muy diversa - sobre energía, pesca, vías de comunicación, derechos humanos, etcétera-. Lagoni, Rainer, "Umweltvölkerrecht, Anmerkung zur Entwicklung eines Rechtsgebietes", en Thieme et al. (comps.), Umweltschutz im Recht, Berlín, 1988, pp. 237 y 238; y Graf Vitzthum, Wolfgang, "Raum, Umwelt und Wirtschaft im Völkerrecht”, en Graf Vitzthum, Wolfgang (ed.), Völkerrecht, Berlín, W de G, 1997, pp. 461 y 462.

2 Debe advertirse que a pesar de que el DIPMA se ha desarrollado, siguiendo el ejemplo del derecho nacional de la materia, cada día las normas e instrumentos de éste se encuentran seriamente determinadas por obligaciones internacionales. Véase al respecto: Hahn, Robert W. y Richards, Kenneth R., "The Internationalization of Environmental Regulation", Harvard International Law Journal, vol. 30, 1989, p. 423.

3 Ipsen, Knut, Völkerrecht, München, C. H. Beck, 1990, p. 806. 
Varios fueron los motivos que dieron lugar a la internacionalización del derecho medioambiental. La toma de conciencia en los ámbitos científico, económico y político sobre los efectos que la explosión demográfica, una posible guerra atómica, y el aumento en los consumos de energía, tenían y podían llegar a tener sobre el equilibrio natural de un mundo que cuenta con recursos y territorio limitados, llevó a la comunidad internacional a tomar conciencia de que para alcanzar una adecuada protección del medio ambiente resultaba necesario el uso del instrumentario del DIP. Asimismo, una regulación internacional del medio ambiente fue considerada como indispensable cuando los Estados nacionales se vieron en la necesidad de superar los conceptos de soberanía e integridad territorial, con el objeto de controlar los daños al medio ambiente que repercuten en su territorio, pero que se originan en el territorio de otros Estados.

\section{DESARROLLO HISTÓRICO}

\section{La etapa anterior a la Conferencia de Estocolmo ${ }^{4}$}

No obstante que el DIPMA como rama especial del DIP es relativamente joven, los problemas ambientales han sido objeto de regulación por las normas de éste desde hace mucho tiempo. El Tratado Jay firmado el 19 de noviembre de 1794 entre Estados Unidos de América y la Gran Bretaña, que regulaba diversos aspectos sobre el alta mar, se suele mencionar como el primer tratado internacional en materia del medio ambiente..$^{5}$ A partir del siglo XIX se firmaron en América del Norte ${ }^{6}$ y posteriormente en Europa un número considerable de tratados que tuvieron por objeto regular la problemática relativa a la conservación de la calidad de las aguas de los ríos internacionales y aguas fronterizas, así como del acceso equitativo a los recursos naturales que se encuentran a disposición en dichos ríos y aguas.

4 Más sobre este periodo puede verse en: Brown Weiss, Ernst, "International Environmental Law: Contemporary Issues and the Emergence of a New World Order", Goergetown Law Journal, núm. 81, 1993, p. 675.

5 El texto aparece en: Parry, C. (comp.), “The Consolidated Treaty Series”, Bd., núm. 52, p. 243.

6 Por ejemplo, el Webster-Asburton Treaty de 9 de agosto de 1842; el Washington-Treaty de 8 de mayo de 1851; el Boundary Waters Treaty de 11 de enero de 1909; el Tratado entre México y Estados Unidos de América sobre el Río Grande, de 3 de febrero de 1942, y el Great Lakes Water Quality, de 15 de abril de 1972. 
Asimismo, en el periodo anterior a 1972 se concluyó una serie de tratados internacionales relativos a la protección de la flora y la fauna, cuyas disposiciones no permitían todavía una defensa suficiente de las especies. Dignos de mención son el Acuerdo para la Protección de las Aves de 19 de marzo de 1902, diversos tratados para la protección de las focas, y el relativo a la pesca de ballenas de 24 de agosto de 1931.

En los acuerdos internacionales sobre el mar que se concluyeron con anterioridad a la Convención de Ginebra de 1958 — con excepción del Tratado sobre la Prevención de la Contaminación de los Mares por el Petróleo de 12 de mayo de 1954 - la materia de la protección medioambiental del mar apenas tuvo un poco de importancia.

Respecto a la protección del aire y de la contaminación transfronteriza con deshechos tóxicos, la misma no fue objeto de regulación internacional sino hasta principios de los años setenta del siglo XX.

Hasta principios de los setenta, la protección ambiental mediante el instrumentario del DIP se limitó a la defensa de determinados elementos del medio ambiente, principalmente de las aguas, y su objeto fundamental fue la defensa de los medios y especies de la naturaleza con mira a satisfacer las necesidades de explotación de los recursos naturales. ${ }^{7}$ Además, los tratados que se concluyeron en esta época fueron más bien bilaterales o regionales y sus instrumentos fueron más represivos que preventivos.

\section{La etapa entre las conferencias de Estocolmo}

\section{y la de Río de Janeiro}

La Conferencia de las Naciones Unidas de Estocolmo celebrada entre el 5 y el 16 de junio de 1972, puede ser señalada como el punto de partida del DIPMA propiamente dicho. En dicha conferencia, la comunidad internacional - aunque sin la participación del bloque de países comunistas- se ocupó por vez primera en la historia de la humanidad de manera especial de los problemas medioambientales.

Como resultado de la Conferencia de Estocolmo, se emitió una declaración - Declaration of the United Nations Conference on the Human Environment—,${ }^{8}$ la cual está integrada por un catálogo de principios cla-

7 Beyerlin, Ulrich, "Rio-Konferenz 1992: Beginn einer neuen globalen Umweltrechtsordnung”, ZaöRV, núm. 54, 1994, p. 126.

8 Esta declaración que fue aprobada por 103 votos, 12 abstenciones y ningún voto en contra, se encuentra disponible en: International Legal Materials (ILM) 11, 1972, p. 1416 y en UN Doc. A/CONF. 48714. 
ramente formulados - los que en algunas ocasiones reproducen los principios del derecho consuetudinario internacional $-9{ }^{9}$ y un plan de acción —Action Plan for the Human Environment- ${ }^{10}$ que se formuló en forma de recomendaciones. Estos documentos internacionales carecieron de obligatoriedad jurídica.

Como consecuencia inmediata del éxito que alcanzó la Conferencia de Estocolmo, en diciembre de 1972 se emitió el PNUMA. A partir de su creación, éste participó de manera muy activa y frecuente como órgano de la Asamblea General de la ONU en asuntos relativos a la regulación medioambiental internacional.

Una característica propia del DIPMA, a partir de la Conferencia de Estocolmo, fue la conclusión de una serie de instrumentos que, aunque por su forma muestran las mismas características de un tratado internacional, sin embargo no resultan obligatorios para los Estados parte -instrumentos de soft law-.

Durante los veinte años que transcurrieron entre la Conferencia de Estocolmo y la de Río, se han negociado y concluido una serie de tratados internacionales sobre materias que anteriormente no se encontraban reguladas, entre otros cabe mencionar:

a) El Tratado de Ginebra sobre la Contaminación del Aire Transfronterizo del 13 de noviembre de $1979,{ }^{11}$ con tres protocolos: de $1985,{ }^{12}$ de $1988^{13}$ y de $1991 .{ }^{14}$

b) El Tratado de Viena sobre la Protección de la Capa de Ozono de 22 de marzo de $1985,{ }^{15}$ con su Protocolo de Montreal de 16 de septiembre de $1987 .{ }^{16}$

c) La Convención del Derecho del Mar de 10 de diciembre de 1982. ${ }^{17}$

d) Los Acuerdos de la Organización Internacional de Energía Atómica, sobre Información y Asistencia en caso de Accidentes Nucleares de 26 de septiembre de $1986 .^{18}$

9 Así, por ejemplo, el artículo 21 de la Declaración de Estocolmo que se refiere a los daños ambientales transfronterizos, no resulta más que una formulación escrita de la práctica consuetudinaria internacional.

10 Artículos 26 y ss.

11 ILM, vol. 18, 1979, p. 1442.

$12 I L M$, vol. 27, 1988, p. 701.

$13 I L M$, vol. 28, 1989, p. 214.

$14 I L M$, vol. 31, 1992, p. 573.

15 ILM, vol. 26, 1987, pp. 1516, 1519.

16 Ibidem, pp. 1541-1550.

17 ILM, vol. 21, 1982, p. 1261.

$18 I L M$, vol. 25, 1986, pp. 1370, 1377. 
e) La Convención de Basilea sobre el Control de Transporte Transfronterizo de Materias Peligrosas. ${ }^{19}$

Muy a pesar del intenso trabajo legal en el ámbito internacional, no fue posible evitar la terrible deforestación de que son objeto los bosques ${ }^{20}$ el amenazante crecimiento de los desiertos; ${ }^{21}$ el calentamiento del planeta; ${ }^{22}$ el crecimiento del hoyo de la capa ozono; y la pérdida de la biodiversidad. ${ }^{23}$ Asimismo, en esta época tuvieron lugar los grandes desastres ecológicos de Amoco Cádiz, Exxon Valdez, Soveso, Bophal, Tschernobyl y Basilea ante los que las normas internacionales resultaron insuficientes.

Por otra parte, muchos de los tratados internacionales emitidos en este periodo hicieron patente que los Estados sólo aceptan someterse a obligaciones internacionales cuando ello no implique la adopción de medidas que lastimen sus intereses nacionales. ${ }^{24}$

Por lo que hace a los aspectos positivos de esta primera etapa del DIPMA, cabe destacar básicamente tres. En principio, la introducción de mecanismos de carácter preventivo; en segundo lugar, los Estados se han mostrado cada vez más dispuestos a utilizar los recursos naturales, tomando en consideración las necesidades de la protección y regeneración del medio ambiente, y no sólo las necesidades inmediatas de aprovechamiento de los recursos naturales; y, finalmente, cuando los Estados no pueden establecer estándares comunes de regulación ambiental, se muestran más dispuestos a contraer obligaciones de cooperación, en forma de acceso e intercambio de información, consultas, y mecanismos de solución de controversias. Incluso los Estados han aceptado someterse a mecanismos de control internacional del cumplimiento de sus obligaciones. ${ }^{25}$

19 ILM, vol. 30, 1989, p. 657.

20 Dicha pérdida ha sido estimada en 17,000 kilómetros cuadrados anuales.

21 En dos décadas, los desiertos crecieron en 120 millones de hectáreas.

22 Producto del crecimiento de los gases de efecto invernadero, que de 1972 a 1990 aumentaron de 16,000 a 23,000 toneladas.

23 Remiro Brotóns, Antonio y otros, Derecho internacional, Madrid, MacGraw-Hill, 1997, p. 1127.

24 Beyerlin, Ulrich, op. cit., nota 7, p. 130; y "Developments in the Law. International Enviromental Law", Harvard Law Review, núm. 104, 1991, p. 1491.

25 Beyerlin, Ulrich, op. cit., nota 7, p. 131. 


\section{La conferencia de Río de Janeiro}

Como resultado de la Conferencia de Naciones Unidas de Río de Janeiro sobre Medio Ambiente y Desarrollo, que tuvo verificativo entre el 3 y el 14 de junio de 1992, ${ }^{26}$ fueron concluidos cinco documentos:

a) La Declaración de Río de Janeiro. ${ }^{27}$

b) Los Principios Generales de la Conservación de los Bosques. ${ }^{28}$

c) La Agenda $21 .{ }^{29}$

d) La Convención sobre Cambio Climático. ${ }^{30}$

e) El Convenio sobre la Diversidad Biológica. ${ }^{31}$

Los tres primeros documentos no contienen disposiciones obligatorias, sólo obligaciones político-morales, por lo que se deben considerar documentos de soft law; en cambio, los dos últimos son realmente auténticos tratados internacionales.

Tanto en la Declaración de Río ${ }^{32}$ como en la Agenda $21,{ }^{33}$ se regula a detalle las características y alcances de un principio que desde hace algún tiempo viene cobrando una significación importante en el derecho ambiental, nos referimos al principio de "desarrollo sustentable". Por éste se entiende un tipo de desarrollo en donde los objetivos de las políticas de desarrollo económico, bienestar social y medioambiental se diseñen de tal forma que resulten consistentes entre sí y con base en una perspectiva de largo plazo. ${ }^{34}$ Esto refleja el interés que la comunidad internacional ha puesto en que el desarrollo económico garantice que las condiciones necesarias que cumple el medio ambiente para la subsistencia de la humanidad no se deterioren, ${ }^{35}$ y que las necesidades de desarrollo económico

26 Ésta ha sido la conferencia de mayor alcance que jamás haya organizado la ONU. En ella participaron más de 30,000 participantes de 176 países, incluidos 103 jefes de Estado o de gobierno. Véase al respecto: Report of the United Nations Conference on Environment and Development, UN Doc. A/CONF: 151/26/Rev. 1, vols. I-II, 1993.

27 ILM, vol. 31, 1992, p. 876.

28 Ibidem, p. 882.

29 A/CONF. 151/26, vols. I y III.

30 Op. cit., nota 27, p. 851. En México, ratificado por el Senado el 3 de diciembre de 1992 y publicado mediante decreto del Diario Oficial de la Federación de 13 de enero de 1993.

31 Ibidem, p. 822. En México, ratificado Senado el 3 de diciembre de 1992 y publicado mediante decreto del Diario Oficial de la Federación de 13 de enero de 1993.

32 Principio 1.

33 Capítulo 39.

34 Sobre el concepto de desarrollo sustentable, véase Rojas, Víctor, La protección del medio ambiente en el TLCAN y la OMC, México, Oxford University Press, 2000, pp. 85-95.

35 Beyerlin, Ulrich, op. cit., nota 7, p. 139. 
consideren los intereses tanto de las generaciones presentes como de las futuras. ${ }^{36}$

Por otra parte, la Declaración de Río prevé algunos principios que se han venido desarrollando en el último tiempo en el derecho ambiental nacional, como conceptos básicos del futuro DIPMA. En concreto, nos referimos a la participación directa de la ciudadanía en la discusión de la problemática ambiental; ${ }^{37}$ el examen del impacto ambiental de los contratos privados y públicos; ${ }^{38}$ el principio de previsión, ${ }^{39}$ y el principio de causación. ${ }^{40}$

En el aspecto institucional, cabe destacar la intención de establecer los mecanismos necesarios para coordinar el trabajo de las organizaciones de la ONU en materia ambiental, por un lado, y la creación de la Comisión de Desarrollo Sustentable, por el otro. ${ }^{41}$

\section{FUENTES}

Según lo dispuesto por el artículo 21 de la Declaración de Estocolmo, las fuentes del DIPMA son las mismas que las del DIP. Las fuentes del DIP se encuentran enumeradas en el artículo 38 del Estatuto de la Corte Internacional de Justicia. La Corte Internacional de Justicia es uno de los órganos permanentes de la Organización de las Naciones Unidas (ONU). El Estatuto de la Corte Internacional de Justicia, según lo dispuesto por el artículo 93, numeral 1, de la Carta de las Naciones Unidas, es obligatorio para todos los Estados miembros de la ONU. Las fuentes mencionadas en aquella disposición se encuentran también reconocidas por los Estados que no pertenecen a la ONU. En dicha disposición podemos diferenciar entre fuentes primarias y fuentes secundarias. Las primarias son los tratados internacionales, la costumbre internacional y los principios generales del derecho. Entre las secundarias se encuentran las decisiones judiciales de los tribunales internacionales y las opiniones de la doctrina del DIP. Todavía se discute si existe jerarquía entre las fuentes del DIP. Mientras un grupo de autores sostiene que la jerarquía se determina con base en el

\footnotetext{
36 Principio 3 de la Declaración de Río.

37 Principio 10.

38 Principio 17.

39 Principio 15.

40 Principio 16.

41 Capítulo 38 de la Agenda 21.
} 
orden en que las fuentes han sido enumeradas en el artículo 38 del Estatuto de la Corte Internacional de Justicia, otros son de la idea que todas las fuentes tienen la misma jerarquía. Además, en la praxis de esta nueva rama especial ha venido cobrando significado un tipo de documentos no obligatorios en el DIP conocidos con el nombre de instrumentos de soft law, a los que algunos autores le han llegado a reconocer el carácter de fuente del DIP de segundo orden. ${ }^{42}$ En ocasiones, también se menciona como fuente del DIPMA - a nuestro juicio erróneamente- al conjunto de normas que, aunque provienen de cuerpos normativos de derecho nacional, se aplican con efectos extraterritoriales. ${ }^{43}$

\section{Tratados internacionales}

Los tratados internacionales son acuerdos de voluntades en forma escrita entre sujetos del DIP con la intención de regular con base en normas del DIP sus relaciones internacionales. ${ }^{44}$ Las normas básicas sobre los tratados internacionales se encuentran codificadas en la Convención de Viena sobre Derecho de los Tratados ${ }^{45}$ y en la Convención de Viena sobre Derechos de los Tratados entre Estados y Organizaciones Internacionales o entre Organizaciones Internacionales. ${ }^{46}$

Según los dos tratados anteriormente mencionados, tanto los Estados como las organizaciones internacionales poseen capacidad legal para concluir tratados internacionales, ${ }^{47}$ y sólo pueden ser objeto de las obligaciones que en ellos se encuentran previstas, cuando las han consentido de manera expresa. ${ }^{48}$

Los tratados internacionales han llegado a ser el instrumento preferido para regular la protección medioambiental internacional ${ }^{49} \mathrm{y}$ al que sin

42 Así, por ejemplo: Ehricke, Ulrich, "Soft law-Aspekte einer neuen Rechtsquelle”, Neue Juristische Wochenschrift, 1989, pp. 1906 y ss., y Eisemann, "Le Gentlemens agreement comme sourde du droit international", Journal de Droit International, 1979, pp. 326 y ss.

43 Este sería el caso de la ley estadounidense: Marine Manual Protection Act, 16, USC, parágrafos 1371-1377, que permite la aplicación de sanciones indirectas de carácter extraterritorial cuando la legislación de un país no cuenta con estándares mínimos de protección de algunas especies marinas.

44 The Vienna Convention on the Law of Treaties, artículo 2o., para. I, (a).

45 Firmado en Viena el 23 de mayo de 1969, en vigor a partir del 27 de enero de 1980. El texto se puede ver en: http://www.jus.vio.no/lm/un.law.of.traties.convention.1969/doc.htm.

46 ILM, vol. 25 , pp. 549 y ss.

47 Artículo 6o. de ambos tratados.

48 Artículo 34 de ambos tratados.

49 Una lista de 68 tratados y convenios internacionales en materia medioambiental firmados por México hasta 1997 se encuentra disponible en: http://www.ine.gob.mx/dgra/ucci/coop_inter/convenio.htm. 
duda se deben los mayores adelantos en la materia. Para 1992 se habían concluido más de mil tratados internacionales relativos a la protección del medio ambiente, de los cuales la mayoría fueron negociados y firmados durante los 20 años inmediatos anteriores. ${ }^{50}$ La preferencia hacia los tratados se debe a que requieren una negociación previa entre las partes obligadas, el contenido de las obligaciones concertadas se establece de una manera más precisa, que en el caso de la costumbre internacional o de acuerdos no escritos, además de que ellos requieren un consentimiento afirmativo y expreso. ${ }^{51}$

En el ámbito universal, como objeto de regulación de los tratados internacionales del DIPMA, encontramos materias tales como: comercio de especies en peligro de extinción; ${ }^{52}$ contaminación del aire; ${ }^{53}$ transporte de materiales peligrosos; $;{ }^{54}$ contaminación de los océanos; ${ }^{55}$ contaminación ocasionada por barcos; ${ }^{56}$ contaminación del medio ambiente marino; ${ }^{57}$ contaminación de los ríos y aguas interiores $;{ }^{58}$ y medio ambiente del Antártico. ${ }^{59}$ Además, en la Conferencia de Río los Estados firmaron un

50 Tan sólo en los últimos diez años anteriores a 1991 se concluyeron más de 150 tratados internacionales en esta materia. Véase al respecto: United Nations Enviromental Programme, Register of International Treaties and Other Agreement in the Field of the Enviroment-Un Doc. UNEP/G.C. 16/Inf 4, 1991. Por otra parte, podríamos referirnos al ejemplo norteamericano en donde en el periodo que va 1930 a 1969 el gobierno de Estados Unidos de América firmó 10 tratados internacionales sobre esta materia y entre 1970 y 1989, dicha cifra ascendió a 16. Al respecto, véase Hahn, Robert W. y Richards, Kenneth R., op. cit., nota 2, p. 425.

51 O'Connell, Mary Ellen, "Enforcing the New International Law of the Environment", German Yearbook of International Law, vol. 35, 1992, pp. 295 y 296.

52 Convention on International Trade in Endangered Species of Wild Fauna and Flor (CITES), Washington, 3 de marzo de 1973. En vigor a partir del 1o. de julio de 1975, ILM, vol. 12, 1973, p. 1085.

53 Convention on Long-Range Transbourdary Air Polution, Génova, 3 de marzo de 1979. En vigor a partir del 16 de marzo de 1983, ILM, vol. 28, 1989, p. 649.

54 Convention on the Control of Transboundary Movements of Hazardous Wastes and Their Disposal, Basilea, 22 de marzo de 1989, ILM, vol. 28, 1989, p. 649.

55 Convention on Prevention for the Protection of Marine Polution by Dumping of Wastes and Other Matters, Washington, Londres, México, Moscú, 29 de diciembre de 1972, ILM, vol. 11, 1972, p. 1294.

56 International Convention for the Prevention of Pollution from Ships, Londres, 2 de noviembre de 1973, ILM, vol. 12, 1973, p. 1319.

57 United Nation Convention on the Law of the Sea, Montego Bay, 10 de diciembre de 1982, ILM, vol. 21, 1982, p. 1261.

58 Para 1991 se había concluido alrededor de 300 tratados relativos a la protección de ríos, lagos y drenaje de aguas negras. En especial véase: Convention and Statute on the Regime of Navigable Waterways of International Concern, Barcelona, 20 de abril de 1921. League of Nations Treaty Series, vol. 7, 35 .

59 The Antartic Treaty, Washington, 1 de diciembre de 1951. United Nations Treaty Series, vol. 402, p. 71. 
acuerdo relativo a la biodiversidad ${ }^{60}$ y otro al cambio de clima. ${ }^{61}$ En el ámbito regional destacan los relativos a la protección del Mar Mediterráneo; ${ }^{62}$ del Mar Báltico; ${ }^{63}$ de los recursos naturales de África; ${ }^{64}$ y del sudoeste asiático — ASEAN_- ${ }^{65}$ Dos tratados internacionales destacan en cuanto a que su ámbito material de validez no queda limitado a la protección de uno sólo o algunos de los elementos que integran el medio ambiente, sino que por el contrario la protección se extiende a al medio ambiente en general, considerado como una unidad. En principio, se debe mencionar la Convención sobre la Protección del Ambiente acordado por el Consejo de los Países Nórdicos el 19 de febrero de 1974, ${ }^{66}$ y en segundo, al Acuerdo de Cooperación Ambiental de América del Norte, concluido en el marco de las negociaciones del Tratado de Libre Comercio de América del Norte. ${ }^{67}$

Por cuanto hace al método para adquirir obligaciones internacionales contractuales en materia medioambiental, en la actualidad se suele recurrir con gran éxito al sistema de convenciones marco, seguidas de protocolos. En este caso, la obligación internacional se adquiere de manera dosificada en dos etapas. En la primera, las partes negocian en una convención un acuerdo marco framework, el cual conmina a las partes a cooperar en la realización de determinados objetivos de protección medioambiental, y donde no se prevén obligaciones concretas a cargo de las partes. ${ }^{68}$ Posteriormente, las partes de la convención negocian protocolos

60 ILM, vol. 31, 1992, p. 822. Sobre la Convención sobre Diversidad Biológica véase: Meffei, John, "envolving Trends in the International Protection of Species", German Yearbook of International Law, vol. 36, 1993, p. 131.

61 ILM..., cit., nota anterior, p. 851.

62 Barcelona Convention for the Protection of the Mediterranean Sea Against Pollution, 16 de febrero de 1976, ILM, vol. 15, 1976, p. 290.

63 Convention on the Protection of the Marine Environment of the Baltic Sea Area, Helsinky, 22 de marzo de 1974, ILM, vol. 13, 1974, p. 546.

64 African Convention on the Conservation of Nature and Natural Resources, Argelia, 15 de septiembre de 1968 .

65 ASEAN agreement on the Conservation of Nature and Natural Resources. Kuala Lampur, 9 de julio de 1985. El texto del acuerdo se encuentra disponible en http://sedac.ciesin,org/pidb/register/reg-139.rrr.htm. Los países partes de este acuerdo son Brunei, Indonesia, Malasia, Filipinas, Singapur y Tailandia.

66 Convention on the Protection of the Environment, ILM, vol. 13, 1974, p. 591.

67 ILM 32, 1993, pp. 1480 y ss. Sobre el acuerdo véase: Rojas, Víctor, op. cit., nota 34, pp. 174 y ss.; y Bugeda, Beatriz, "Is NAFTA up to its green expectations? Effective law enforcement under the North American Agreement on Environmental Cooperation", University of Richmond, vol. 32, enero de 1995, núm. 5, pp. 1591 y ss.

68 Así, por ejemplo: Vienna Convention for the Protection of the Ozone Layer. ILM, 25, pp. 1529,1532 y 1533 . 
por separado, cada uno de los cuales establece en forma de obligación la ejecución de medidas específicas para el logro de los objetivos propuestos en la convención. ${ }^{69}$ Generalmente, la convención contiene disposiciones que establecen las bases para la adopción de un protocolo. A menudo, el proyecto de protocolo se somete a la secretaría de la organización creada en la convención como adelanto de la reunión en la que se someterá a discusión; posteriormente, dentro de cierto plazo, con anterioridad a la reunión en donde se decidirá su adopción, la secretaría se encarga de enviar a las partes el protocolo propuesto. Si las partes no alcanzan el consenso, es posible que una mayoría calificada — habitualmente tres cuartas partes o dos terceras partes - decidan sobre su adopción. ${ }^{70}$ Este procedimiento por etapas resulta efectivo, debido a que la convención no hace nacer obligaciones directamente exigibles de los Estados parte, aunque éstos si quedan, en cambio, comprometidos a negociarlas en un futuro. Además, la convención crea una estructura institucional de cooperación y negociación de la que pueden valerse los Estados para concluir rápidamente nuevos protocolos, cuando nuevas evidencias científicas demuestren la necesidad de una actualización de la regulación ambiental y antes de que los daños que ya se hayan comenzado a producir se agudicen y lleguen a ser irreversibles.

Sin embargo, la negociación de acuerdos internacionales en forma de protocolos tiene ciertas desventajas. En principio, requiere de dos rondas de negociaciones y de ratificaciones. En algunos casos, esto puede significar mucho tiempo antes de poder evitar daños ambientales que ya se hayan iniciado con anterioridad a la negociación de la convención. Si este último es el caso, no resulta recomendable éste método. ${ }^{71}$ Por otra parte,

69 Así, por ejemplo: Montreal Protocol on Substances that Deplete the Ozone Layer. ILM, 26, p. 1541, que se negoció para fijar los medios necesarios para alcanzar los objetivos de la Vienna Convention for the Protection of the Ozone Layer.

70 "Developments in the Law. International Enviromental Law", op. cit., nota 24, p. 1528.

71 Este es el caso de lo que ha sucedido con la Convención de Cambio Climático y su Protocolo de Kioto. La Convención quedó concluida desde 1992 y forma parte de los acuerdos adoptados en la Conferencia de Río. La primera conferencia de los Estados parte se llevó a cabo en Berlín, entre el 28 de marzo y el 7 de abril de 1995; la segunda se celebró en Ginebra entre el 9 y el 16 de julio de 1996; el tercer periodo de sesiones se llevó a cabo del 1 al 11 de diciembre de 1977, en Kioto, Japón. El 11 de diciembre de 1997 se adoptó el Protocolo de Kioto. En éste se imponen obligaciones cuantificadas de reducción de emisiones, lo que deberá llevar a los países desarrollados en su conjunto a reducir sus emisiones de gases de efecto invernadero en un 5.2\%, respecto de sus niveles de emisiones que tenían en 1990. Para que el protocolo entre en vigor se requiere la ratificación de cuando menos 55 países que representen el 55\% de las correspondientes emisiones. Hasta febrero de 2000, 84 países habían firmado el protocolo, de los cuales sólo 22 lo habían ratificado. Con el anuncio que hiciera el presi- 
el mismo puede ser utilizado como una forma de alentar la negativa de cooperación de los Estados, toda vez que éstos bien pueden estar dispuestos a ser parte de la convención, sin participar en la negociación de los protocolos. Quizá este último problema se pudiera superar, exigiendo de los Estados que participaron en la convención que en el futuro también participen en la negociación de cada uno de los protocolos. ${ }^{72}$ Finalmente, posiblemente este método resulte poco efectivo para poder alcanzar integralmente todos los objetivos que se plantean en la convención, toda vez que con base en la misma se negocian una multitud de protocolos. ${ }^{73}$

Algunos juristas han establecido que los tratados del DIPMA son en su mayoría treaty-laws en oposición a los treaty-contracts, debido a que han sido concluidos en interés general de la sociedad y no se basan como aquellos en el principio de reciprocidad. Por lo mismo, sus normas son de carácter regulatorio más que recíprocas, pues en ellas se prevén obligaciones que están destinadas a proteger el interés común de la humanidad en sí mismo, y no sólo en la medida en que los Estados se encuentren dispuestos a contraer obligaciones recíprocas. ${ }^{74}$

Otro punto que cabe destacar en el derecho de los tratados del DIPMA es la erosión que está sufriendo el principio del consentimiento unánime, por lo que hace al nacimiento de las obligaciones internacionales. Según lo dispuesto por los artículos 11 y 41 de la Convención de Viena del Derecho de los Tratados, el consentimiento de un Estado es supuesto indispensable para contraer las obligaciones internacionales que nacen con base en tratados internacionales. Sin embargo, poco a poco comienzan a aparecer en el DIP formas que permiten el nacimiento de obligacio-

dente de Estados Unidos de América, George W. Bush, en marzo de 2001, en el sentido de que su país no ratificará el protocolo por no ser compatible con los intereses económicos de su nación, se está en riesgo de volver al mismo estado que existía en 1992. Véase al respecto: Rivera, Alicia, "El cambio climático, el calentamiento de la tierra”, Debate, Madrid, 2000.

72 Aun cuando se prevea una disposición de este tipo, no existe garantía de que los Estados parte de la convención estarán dispuestos en el futuro a suscribir los protocolos que puedan estar en contra de sus intereses nacionales. Así, por ejemplo, según la Convention on International Trade in Endangered Species, los Estados parte pueden hacer valer reservas para negarse a cambiar su lista de especies protegidas, tal como lo ha hecho el gobierno de Japón con respecto a las ballenas, y cinco países africanos con respecto a los elefantes. Al respecto, véase "Developments in the Law. International Enviromental Law", op. cit., nota 24, p. 1544.

73 "Developments in the Law. International Enviromental Law", op. cit., nota 24, pp. 15431546.

74 Así, por ejemplo: Kiss, Alexandre y Shelton, Dina, "Object and Nature of International Environmental Law", International Environmental Law, New York, Transnational Publisher, Inc., 1991, pp. 16 y 17. 
nes contractuales aún y cuando no exista el consentimiento previo de las partes. ${ }^{75}$ Este sistema lo adopta, por ejemplo, el Montreal Protocol on Substances that Deplete the Ozone Layer, que prevé en su artículo 2o., fracc. 9, inciso c), que cuando los ajustes de las sustancias contenidas en el anexo del protocolo no se decidan por consenso, tales decisiones podrán ser adoptadas por la mayoría de las dos terceras partes de los miembros presentes, bajo la condición de que los países que integren dicha mayoría representen por lo menos el cincuenta por ciento del consumo de las sustancias controladas. Ciertamente esta nueva tendencia abre la puerta a un desarrollo del DIP sobre bases hasta el momento desconocidas. ${ }^{76}$

Por lo que hace a la naturaleza de las obligaciones contenidas en los tratados del DIPMA, ha resultado útil establecer deberes del tipo bottom up.${ }^{77}$ En este caso, el contenido de la obligación consiste en que se incorpore en la legislación nacional de los Estados parte los estándares medioambientales previstos en el tratado. De esta forma, éstos tendrán entera libertad para fijar los medios y formas necesarias para su consecución con base en sus propias políticas ambientales, y utilizando su propio instrumentario. ${ }^{78}$ Este tipo de obligaciones contribuye de manera muy especial a la nueva idea de coordinación del moderno DIPMA que tiene por objeto armonizar los contenidos de las legislaciones nacionales y ofrecer a los particulares medios de protección frente al Estado. Para que el abandono del cumplimiento de la obligación internacional a los medios del derecho interno de los Estados parte no implique sustraer por completo al control internacional el cumplimiento de dichas obligaciones, resulta común que cuando se establece este tipo de obligaciones se dé participación a los organismos internacionales para que sirvan como institución de apoyo, tanto en la fase de la preparación de la legislación interna, como

75 Así sucede también, por ejemplo, según lo dispuesto por las normas de la International Labor Organization y de la International Civil Aviation Organization, las que permiten con una mayoría calificada — dos terceras partes - la adopción de reformas.

76 Palmer, Geoffrey, "New Ways to Make International Environmental Law", American Journal of International Law, vol. XXX, núm. 5, 1991, pp. 270-278.

77 Así, por ejemplo: Sebenius, K., "Crafting a Winning Coalition: Negotiatin a Regime to Control Global Warming", Greenhouse Warming, 1991, pp. 69, 71; y Nitze, L., "A Proposed Structure for an International Convention on Climate Change”, Greenhouse Warming, 1991, p. 110.

78 Este es precisamente el método que utiliza el Acuerdo de Cooperación Ambiental para América del Norte, el que en sus artículos 5o., 6o. y 7o. establece como obligaciones de los Estados que sus legislaciones internas prevean ciertos instrumentos que garanticen la eficacia de las normas de la materia. Véase al respecto: Rojas, Víctor, op. cit., nota 34, pp. 183 y ss. 
en la de su aplicación. Éstos suelen recolectar y distribuir información, y prestan asistencia técnica, científica y administrativa a los países que lo requieran.

Cabe destacar el hecho que a partir de la Conferencia de Río se han venido desarrollando en los tratados del DIPMA una serie de nuevos instrumentos preventivos y sancionadores que mediante el intercambio de información, consultas y trabajo en común tienen por objeto asegurar el cumplimiento de las obligaciones contenidas en los mismos. En general, se puede constatar que mediante un adecuado sistema de intercambio de informaciones se abre el camino para un trabajo efectivo en común de carácter preventivo. ${ }^{79}$

Un aspecto de vital importancia que contribuirá a alcanzar la efectividad de las normas de este tipo de acuerdos, será sin duda el establecimiento de cláusulas que prevean la fuente de los recursos financieros que resulten necesarias para el cumplimiento de las obligaciones previstas en el tratado. Esto requiere de instrumentos económicos tales como el debtfor-natur-swap ${ }^{80}$ que permitan compensar las pérdidas económicas que se generen con motivo del cumplimiento de las obligaciones contenidas en los tratados en cuestión. ${ }^{81}$

En la práctica jurídica del derecho de los tratados del DIPMA, se ha demostrado que los Estados se encuentran más dispuestos a formar parte de los mismos cuando prevén obligaciones para cooperar en la solución de problemas medioambientales, si ellos establecen la posibilidad de hacer valer cláusulas de escape, y si los mismos cuentan con procedimientos y normas claras que aseguren su cumplimiento, lo que posiblemente requiera la existencia de una organización internacional. ${ }^{82}$

79 Véase, por ejemplo, los artículos 5o. y 17 de la Convención sobre Biodiversidad; el artículo 10 de la "UN Convention on the Transboundary Effects of Industrial Accident", ILM, vol. 31, 1992, pp. 1330 y ss.; los artículos 4o. y 6o. de la "UN Convention on the Protection and Use of Transboundary Watercosuses and International Lakes", ILM, 1992, pp. 1312 y ss. En el derecho interno medioambiental se han desarrollado de forma correlativa mecanismos que implican nuevas formas de cooperación entre los Estados y la industria, mismos que pueden ser acuerdos opcionales entre los Estados y las agrupaciones industriales o ramas industriales particulares, y que se encuentran sujetos al régimen del derecho civil. Rest, Albert, "Neue Mechanismen der Zusammenarbeit und Sanktionerung im internationalen Umweltrecht", Natur und Recht, 1994, pp. 271 y ss.

80 Mediante este sistema, un organismo internacional en materia ambiental compra deuda externa y libera de la misma a un Estado, el cual a cambio adquiere determinados compromisos medioambientales.

81 "Developments in the Law. International Enviromental Law", op. cit., nota 24, pp. 15291534.

82 Ibidem, pp. 1566-1573. 
Un déficit que caracteriza a los tratados del DIPMA es que regularmente carecen de mecanismos eficientes para el aseguramiento de sus normas, tales como mecanismos institucionales de solución de controversias. Cuando éstas llegan a existir, la falta del carácter obligatorio de las resoluciones de los órganos; la falta de provisiones sobre el financiamiento de las tareas a realizar, y la existencia de cláusulas de escape para evadir el cumplimiento de las obligaciones, puede hacer nugatorias las obligaciones contraídas. Esta circunstancias no son más que el reflejo de la actitud de los Estados que se niegan a ceder sus facultades sobre la protección del medio ambiente y el control de sus normas a órganos de solución de controversias internacionales. ${ }^{83}$

Un rasgo importante que se encuentra en el fondo de este tipo de tratados es el hecho de que la decisión política que lleva a su conclusión, normalmente se encuentra motivada o determinada en gran medida por evidencias científicas. ${ }^{84}$

\section{La costumbre internacional}

La costumbre internacional constituye una fuente jurídica no escrita que cuenta con dos elementos constitutivos: uno objetivo y otro subjetivo. El elemento objetivo - consuetudo- consiste en una práctica general. ${ }^{85}$ El elemento subjetivo _opinio iuris - es el reconocimiento de dicha práctica general como jurídicamente obligatoria. ${ }^{86}$ La costumbre internacional puede surgir mediante un hecho positivo: una conducta o de-

83 O'Connell, Mary Ellen, op. cit., nota 51, p. 301.

84 Hahn, Robert W. y Richards, Kenneth R., op. cit., p. 434, y "Developments in the Law. International Enviromental Law", op. cit., nota 2, pp. 1529-1534.

85 En cuanto a la práctica general, se requiere una conducta de los Estados que haya tenido cierta duración, unidad y difusión. Resulta suficiente para la conformación de esta práctica general que la mayor parte de los Estados se comporte de una forma determinada. Conductas contrarias específicas a la práctica general no pueden ser capaces de dañar la unidad requerida. A pesar de que un Estado, de manera reiterada, mediante actos o manifestaciones, se oponga a una costumbre internacional — persistent objector - no destruye a la misma como tal, sin embargo, éste no se encuentra obligado por la misma.

86 Por cuanto hace a la opinio iuris, la mayoría de los Estados debe encontrarse convencida de que su conducta la ha llevado a cabo en el pasado y la llevará a cabo en el futuro, debido a que la misma es obligatoria en los términos del DIP. Si sólo existe la práctica general sin el convencimiento jurídico, no existe una norma de costumbre del derecho internacional público, sino una norma de cortesía que se cumple por que así lo exigen los buenos modales, la cortesía y la hidalguía. Este último es el caso de los honores protocolarios cuando se recibe a altos funcionarios de un Estado extranjero o la publicación de una nota diplomática, sólo hasta que el destinatario de la misma la ha recibido. 
claración, o mediante una abstención. Un tratado internacional también puede fundar costumbre internacional cuando Estados que no son partes del acuerdo se comportan según lo exigido por las disposiciones del mismo. Asimismo, el derecho consuetudinario puede ser puesto fuera de vigor mediante un tratado internacional. Existen dudas sobre si los nuevos Estados que ingresan a la comunidad internacional se encuentran obligados por la costumbre internacional existente. Según la "teoría del orden jurídico preexistente", el derecho consuetudinario es válido para todos los sujetos del DIP, y también para los Estados que recién ingresan a la comunidad internacional. Según la "teoría de consenso necesario", la obligatoriedad de una costumbre existente para los nuevos Estados requiere su aceptación, ya expresa, ya tácita. La ONU ha creado un organismo: la International Law Commission que tiene por objeto codificar la costumbre internacional. La codificación de dichas costumbres no cambia su carácter de costumbre internacional.

Los tratadistas del DIP son los encargados de descubrir las normas consuetudinarias mediante la observación de las prácticas del DIP, o bien analizando los principios que comúnmente aparecen en los tratados internacionales, las declaraciones e instrumentos jurídicos de carácter no obligatorio, y las decisiones de los tribunales internacionales. Al ser los internacionalistas los encargados de avalar y legitimar las normas de costumbre internacional, no resulta raro que tiendan a privilegiar los intereses de algunos Estados sobre los de otros, y que en ocasiones reconozcan como costumbres internacionales de carácter universal a prácticas a las que sólo se les reconoce fuerza obligatoria por algunos Estados. ${ }^{87}$

A diferencia de lo que sucede con el derecho de los tratados, el derecho de costumbre internacional medioambiental se ha desarrollado en el último tiempo sólo de manera lenta y poco significativa. Esto se entiende, debido a que cada vez más los Estados prefieren regular sus relaciones internacionales con base en tratados internacionales. Lo que se debe a que éstos ofrecen una mayor seguridad jurídica que caracteriza a las obligaciones del derecho consuetudinario. ${ }^{88}$ Con los tratados, sin embargo, se puede perder la flexibilidad y capacidad de evolución que caracteriza a la costumbre internacional.

Por otra parte, se puede decir que las normas del derecho internacional consuetudinario sólo ofrecen una protección modesta al medio am-

87 "Developments in the Law. International Enviromental Law", op. cit., nota 24, p. 1506.

88 Ipsen, Knut, op. cit., nota 3, p. 849. 
biente. ${ }^{89}$ A diferencia de lo que sucede con el DIPMA de los tratados, el derecho de costumbre internacional aporta muy poco al DIPMA.

Las normas consuetudinarias del derecho internacional del medio ambiente se suelen clasificar en tres grandes rubros: en primer lugar se encuentran las normas materiales; en segundo las normas procesales; y, finalmente, aquellas relativas a la responsabilidad internacional en casos de daños al medio ambiente. ${ }^{90}$

\section{A. Normas materiales}

Entre las normas materiales, encontramos el principio según el cual a los Estados no les es permitido llevar a cabo conductas, o permitir que en el territorio donde ejercen su poder soberano se lleven a cabo conductas que tengan por resultado un daño significativo ${ }^{91}$ al medio ambiente del territorio, espacio, o aguas que se localizan fuera de sus fronteras. ${ }^{92}$ Esta norma consuetudinaria puede ser concebida como una aplicación concreta del principio de buena vecindad entre los Estados. ${ }^{93}$ Algunos autores ${ }^{94}$ señalan que esta obligación también es de carácter preventivo, de tal forma que los Estados también se encuentran obligados a tomar todo tipo de medidas que impidan la realización de conductas que puedan causar daños ambientales transfronterizos. ${ }^{95}$

Otra norma material de este género es aquella que exige una repartición y acceso equitativo a los recursos naturales comunes a varios Estados — principle of equitable apportionment/utilization- Esta norma se encuentra reconocida expresamente por las normas contractuales del DIP del mar. ${ }^{96}$

89 Palmer, Geoffrey, op. cit., nota 76, p. 265.

90 Ibidem, pp. 855-870.

91 Esto significa que no cualquier daño resulta sancionable. Sólo los daños significativos substantielle son violatorios del DIP. Véase al respecto Sachariew, Mark, "The Definition of the Thresholds of Tolerance for Transboundary Environmental Injury under International Law: Development and Present Status", Netherlands International Law Review, núm. 37, 1990, pp. 193 y ss.

92 Este principio se ha reconocido en el artículo 21 de la Declaración de Estocolmo y anteriormente fue aplicado en los casos: Trail Smelter decidido por un panel binacional canadiense-estadounidense en 1941; así como en el caso Corfu Channel: ICJ Reports, 1949, p. 4.

93 Palmer, Geoffrey, op. cit., nota 76, p. 265.

94 Por ejemplo, Donald, Elliot, "Foreward: A New Style of Ecological Thinking in Enviromental Law”, Wake Forest Law Review, vol. 26, 1991, p. 1; y O'Connell, Mary Ellen, op. cit., nota 51, p. 306.

95 Sobre la responsabilidad de los Estados por daños transfronterizos, véase Ortiz Ahlf, Loretta, "Responsabilidad por daños transfronterizos", Jurídica, núm. 29, 1999, pp. 380-382.

96 Véase al respecto Wolfrum, Rudiger, "Purposes and Principles of International Environmental Law”, German Yearbook of International Law, núm. 33, 1990, p. 318. 
En los últimos años se han venido reconociendo en algunas regiones del mundo ciertas normas de costumbre internacional cuyo contenido concreto todavía no resulta del todo claro. Entre éstas podemos mencionar la obligación de adoptar medidas preventivas — precautionary measures - para evitar daños medioambientales transfronterizos, ${ }^{97}$ y la obligación de proporcionar información relevante cuando un Estado que se encuentre en posibilidad de ser afectado en su medio ambiente por conductas de otro, requiera la misma para tomar medidas preventivas. ${ }^{98}$

\section{B. Normas procesales}

Como normas procesales consuetudinarias se suelen identificar: la obligación que tienen los Estados de informar a las posibles víctimas sobre los daños que por sus conductas, incluidas las actividades que en el futuro se tenga pensado llevar a cabo, se hayan ocasionado o puedan ocasionar en el territorio de otros Estados, ${ }^{99}$ y la obligación de participar en consultas con el propósito de negociar soluciones, cuando el Estado que resulta o puede resultar perjudicado por los problemas ambientales lo solicita del Estado que ocasiona o puede ocasionar el daño. ${ }^{100}$

\section{Normas relativas a la responsabilidad civil}

La obligación derivada del derecho de costumbre internacional relativa a la responsabilidad civil por daños medio ambientales se consagra en el principio 22 de la Declaración de Estocolmo como un objetivo a ser alcanzado por el DIPMA. ${ }^{101}$ Sin embargo, algunos Estados se muestran reticentes a aceptar dicho principio como una obligación a su cargo.

Una obligación de responder por daños medioambientales existe de dos formas: por una parte, en cuanto a los daños que se ocasionen sobre personas privadas o sus bienes; y, por la otra, por lo que hace a los daños

97 Esta obligación se encuentra reconocida en el Principio 21 de la Declaración Mundial de la Naturaleza (37/7 de la Asamblea General de la ONU). Véase al respecto Lagoni, Karl, "Die Abwehr von Gefahren für die marine Umwelt", Berichte der Deutschen Gesellschaft für Völkerrecht, núm. 32, 1992, p. 145.

98 Véase al respecto Handl, Norbert, "Grenzüberschreitendes nukleares Risiko und völkerrechtlicher Schutzanspruch", UTB, Tübingen, 1992.

99 Este principio fue reconocido en el caso "Lake Lanoux", $R$. Int'l Arb, núm. 12, Award 281, pp. 315-316.

100 Ipsen, Knut, op. cit., nota 3, p. 863.

101 Sobre la responsabilidad civil por daños transfronterizos, véase Ortiz Ahlf, Loretta, "Responsabilidad por daños transfronterizos", Jurídica, núm. 29, 1999, pp. 382-388. 
que se ocasionen en bienes patrimoniales de un Estado. En el primer caso, la obligación a cargo del Estado se cumple al prever en su legislación interna, en favor del particular perjudicado, los recursos legales que le permitan obtener la reparación del daño. ${ }^{102}$ En el segundo, la obligación se cumple en los mismos términos, que se cumple cualquier responsabilidad internacional.

En 1986 la Comisión de Medio Ambiente y Desarrollo convocó a un grupo de expertos en derecho del medio ambiente para que prepararan un reporte sobre los principios legales necesarios para la protección del medio ambiente, para el desarrollo sustentable y para el desarrollo del DIPMA. Dicho grupo formuló los principios básicos de la responsabilidad internacional. Se determinó que un Estado resulta culpable en los términos del DIP por el quebrantamiento de una obligación internacional relativa al uso de un recurso natural, a la prevención, o al combate de un problema medioambiental. De ser éste el caso, el Estado culpable deberá dar por terminada la conducta contraria al DIP; de ser posible, reproducir la situación que hubiese existido de no haberse verificado dicha conducta ilícita; pagar por los daños que se ocasionen por dicha conducta; de ser necesario, otorgar satisfacción para resarcir la conducta indebida. ${ }^{103}$

En general, se advierte una tendencia en el DIPMA moderno de privilegiar a las costumbres que impliquen una forma preventiva de cooperación ambiental sobre las costumbres tradicionales que se derivan del principio de buena vecindad.

\section{Principios generales del derecho}

Junto a los principios que en el derecho de costumbre internacional se han desarrollado, algunos principios generales del derecho resultan aplicables al DIPMA. Entre estos se cuentan el principio de la verdad sabida y buena fe guardada, el principio de buena vecindad, la prohibición del mal uso del derecho, el principio de solidaridad de los Estados, y el principio de la herencia común de la humanidad. Éste último resulta aplicable por cuanto hace al uso y aprovechamiento de las zonas internacionales, y no, en cambio, en casos de daños transfronterizos. Algunos autores tam-

102 Una obligación de este tipo, rara vez se encuentra prevista en los tratados internacionales. Véase al respecto: Kimminich, Otto, "Völkerrechtliche Haftung für dasHandeln Privater im Bereich des internationalen Umweltschutzes", Archiv des Völkerrechts, 1984, p. 271.

103 World Commission on Enviroment and Development, Experts Group on Environmental Law, Environmental Protection and Sustainable Development, 1987, p. 32. 
bién incluyen, dentro de los principios generales del DIPMA, a los principios de prevención, así como aquél que sostiene: el que contamina paga; sin embargo, la doctrina permanece escéptica. ${ }^{104}$

\section{4. $E l$ soft law}

El concepto de soft law engloba aquellas norma de conducta internacional establecidas en documentos internacionales que, aunque no son obligatorias, jurídicamente hablando, por no haberse seguido el procedimiento requerido para la conclusión de un tratado internacional, si en cambio, en cuanto a su estructura resultan similares a las de un acuerdo internacional. En la práctica del DIP, las normas de soft law se utilizan cada vez más y su número se incrementa de manera vertiginosa. Esto quizá se deba a que, a pesar de sus debilidades legales, políticamente resultan muy prácticas. ${ }^{105}$ Incluso, en algunos círculos se les ha llegado a considerar este tipo de normas como una nueva fuente del DIP de calidad inferior.

Las normas del soft law resultan particularmente atractivas para el DIPMA, pues suelen servir como el primer paso en la creación de un ambiente que pueda contribuir a la conclusión de instrumentos de hard law que establezcan normas obligatorias a cargo de los Estados. Esto se debe a que el soft law se basa sobre un acuerdo que tiende a uniformar, por lo menos, la consideración política de un problema, no solamente entre los grupos políticos, sino también en la opinión pública, con el propósito de fijar las bases para que en un futuro sea posible el establecimiento de normas obligatorias. De esta forma, las normas del soft law tienden un puente entre la política internacional y el DIP, para facilitar el consenso en vías al establecimiento de nuevas normas internacionales. ${ }^{106}$

104 Véase al respecto Bryde, Brun-Otto, "Umweltschutz durch algemeines Völkerrecht?", Archiv des Völkerrechts, 1993, pp. 1 y ss.; Epiney, Astrid, "Das Verbot erheblicher grenzüberschreitender Umweltbeeinträchtigungen: Relikt oder konkretisierung Grundnorm?”, Archiv des Völkerrechts, 1995, p. 309; y Hinds, Caroline, "Das Prinzip 'sic utere tuo ut alienum non laedas' und seine Bedeutung im internationalen Umweltrecht”, Archiv des Völkerrechts, 1992, pp. 298 y ss.

105 Palmer, Geoffrey, op. cit., nota 76, p. 269.

106 Idem. 


\section{ORGANISMOS INTERNACIONALES}

Los Organismos internacionales (OI) son cuerpos que se forman por sujetos de DIP, que se crean mediante un acuerdo de voluntades de DIP en el que se fijan los objetivos de la organización y los principios del trabajo común. Los OI cuentan con un órgano por lo menos en cuyo seno se forma la voluntad del organismo. La función que cumplen hoy día los OI en la praxis del DIP es de suma importancia; ellos han llegado ha ser un medio que contribuye a la creación y aplicación de las normas del DIP. Asimismo, los OI facilitan la participación de la ciudadanía en la discusión y toma de decisiones para resolver la problemática internacional.

$\mathrm{Al}$ igual que temas tales como el aseguramiento de la paz, los derechos humanos y la liberalización del comercio y de la economía internacional, el tema de la protección del medio ambiente ha llegado a ser un objetivo habitual de los OI. Actualmente, la comunidad internacional acepta sin excepción alguna que en la protección del medio ambiente participen activamente los OI. Esto se debe a que la complejidad de las materias ambientales — que se interrelacionan con la problemática social y económica - hace necesaria una participación más amplia y profunda no sólo de las autoridades nacionales de los Estados involucrados, sino también de los grupos científicos y de la sociedad en general. ${ }^{107}$ Por otra parte, la problemática ambiental requiere de soluciones progresivas que sólo se puede alcanzar mediante la cooperación continua que posibilitan las estructuras institucionales de los OI. ${ }^{108}$ También, los OI dotan a los Estados miembro de una estructura con gran capacidad de reacción que permite ofrecer soluciones para enfrentar las nuevas problemáticas ambientales de una manera más rápida y efectiva.

Las tareas que llevan a cabo los OI en esta materia se refieren menos a la actividad de creación de normas ${ }^{109}$ que a la preparación de la infor-

107 Así, por ejemplo, en el Acuerdo de Cooperación Ambiental de América del Norte se ha creado, como órgano de la Comisión de Cooperación Ambiental, un Comité Consultivo Público Conjunto en el que pueden participar además empleados públicos, científicos y ciudadanos. Véase al respecto Rojas, Víctor, op. cit., nota 34, pp. 224 y 225; y Abbot, Friederick, "The NAFTA Environmental Dispute Settlement System as Prototype for Regional Integration Arrangements", Yearbook of International Environmental Law, vol. 4, 1993, p. 11.

108 Sand, John, "International Cooperation: the Enviromental Experience", en Mathews, J. (comp.), Preserving the Global Environment, New York, 1991, pp. 236, 241.

109 Los OI pueden crear o intervenir de manera indirecta en la creación de normas del DIP de cuatro formas. En principio, pueden influir en la creación de normas de costumbre internacional. En segundo lugar, pueden intervenir en la preparación de conferencias para negociar tratados internacio- 
mación, foros y demás elementos necesarios, que servirán de base para la creación de las normas del DIPMA del futuro, y ayudarán al aseguramiento del cumplimiento de las obligaciones contraídas por los Estados parte. ${ }^{110}$ Por otro lado, destaca la recomendación de estándares, cuya adopción no resulta obligatoria para las partes. ${ }^{111}$ Asimismo, los OI contribuyen a la discusión y toma de conciencia sobre la problemática ambiental, lo que finalmente pretende llegar a constituirse en un medio de presión y sensibilización de la clase política para conminarla a adoptar las medidas necesarias para contar con un medio ambiente sano. ${ }^{112}$ Otra función digna de mención es aquella que consiste en la asistencia ${ }^{113}$ o la fiscalización ${ }^{114}$ del cumplimiento de las obligaciones medioambientales por parte de los Estados. Finalmente, se debe mencionar la investigación y seguimiento de los procedimientos para la resolución de conflictos. ${ }^{115}$

Digno de mención resulta el hecho de que, a causa de que son los individuos y no las formaciones abstractas de tipo legal quienes sufren los efectos producidos por los daños medioambientales, los OI que se ocupan de la problemática del medio ambiente con frecuencia aceptan integrar en sus actividades a organizaciones no gubernamentales. Sin embargo, aún carecen en su mayoría de procedimientos sistemáticos que les permitan considerar los puntos de vista del público en general, ${ }^{116}$ y no sólo los de aquellas organizaciones no gubernamentales de gran tamaño y compleja organización.

nales. Asimismo, los OI pueden emitir decisiones obligatorias para los Estados miembro. Finalmente, pueden emitir resoluciones o recomendaciones no obligatorias soft law, las que pueden servir como medio para la creación de una opinión internacional o para conminar a los Estados a armonizar sus regulaciones internas.

110 Kilian, Michael, Umweltschutz durch Internationale Organisationen. Die Antwort des Völkererchts auf die Krise der Umwelt?, Berlín, Duncker \& Humblodt, 1987, pp. 56, 76 y 77.

111 Sommer, Julia, "Environmental Law-Making by International Organisations", Zeitschrift für ausländisches öffentliches Recht und Völkerrecht, vol. 56, 1996, pp. 602 y ss.

112 "Developments in the Law. International Enviromental Law", op. cit., nota 24, p. 1605.

113 Sand, Peter, "Institution-Building to Assist Compliance with International Environmental Law: Perspectives”, Zeitschrift für ausländisches öffentliches Recht und Völkerrecht, vol. 56, 1996, pp. 774 y ss.

114 Lang, Winfried, "Compliance Control in International Environmental Law: Institutional Necessities”, Zeitschrift für ausländisches öffentliches Recht und Völkerrecht, vol. 56, 1996, pp. 685 y ss.

115 Bayerlin, Ulrich, "State Community Interests and Institution-Building in International Environmental Law”, Zeitschrift für ausländisches öffentliches Recht und Völkerrecht, vol. 56, 1996, p. 613 .

116 "Developments in the Law. International Enviromental Law", op. cit., nota 24, pp. 1600-1604. 
El número de OI con competencia en materia ambiental es asombroso. La característica más importante por lo que hace a las relaciones de los OI de la materia entre ellos mismos es su descentralización. Esto trae como consecuencia que cada uno de ellos se ocupe de la problemática ambiental con sus propios métodos y recursos, sin que cuenten con un órgano coordinador que organice el trabajo de todos ellos. Esto ha traído como consecuencia que entre los diferentes OI que se ocupan de esta materia, exista en ocasiones duplicación de funciones. Por otra parte, como punto positivo de la descentralización de dicho organismos, cabe destacar su gran capacidad para adaptarse a los cambios. ${ }^{117}$ Quizá la forma más efectiva de compensar la falta de centralización de los OI que se encargan de tareas ambientales es simplificar sus procesos de toma de decisión, con el objeto de que sin consenso puedan tomar decisiones que resulten obligatorias para los Estados miembros. Esto requeriría incorporar al derecho de los OI los desarrollos que se han presentado en el derecho y prácticas nacionales e internacionales durante los últimos veinte años. ${ }^{118}$

El artículo 63 de la Carta de las Naciones Unidas establece que el Consejo Económico y Social debe establecer relaciones con todo tipo de organizaciones, creadas mediante acuerdos internacionales intergubernamentales que tengan competencia en materia económica y social. Dicho consejo ha negociado 60 acuerdos con organismos especializados, incluyendo ocho con organismos que cuentan con significativa competencia en materia ambiental. El consejo ha establecido un Comité Administrativo de Coordinación con el propósito de coordinar las actividades de los organismos, sin embargo, éste ha resultado incapaz de hacer frente a su cometido.

En la Convención del Derecho del Mar se aspiró por vez primera a la creación de un OI de carácter supranacional que contara también con competencia en materia de protección del medio ambiente. Dicha supranacionalidad se deriva de la facultad con la que cuenta dicho organismo para emitir su propio derecho. ${ }^{119}$ La actividad legislativa se lleva a cabo por una asamblea, la que toma sus decisiones con base en el principio de mayoría — dos terceras partes - . De esta forma, una autoridad internacional dispone de autonomía para crear derecho ambiental obligatorio. ${ }^{120}$

120 Artículo 209, fracc. 1. 
Ciertamente, ningún organismo será capaz de salvar por sí mismo al mundo de una catástrofe ambiental, y el éxito de su gestión dependerá en todo caso de la decisión y entereza que los Estados pongan en la cooperación tanto en el sector financiero, como en el técnico y el político. ${ }^{121}$

\section{APLICACIÓN DE LAS NORMAS DEL DIPMA}

El DIP, al igual que cualquier otra rama del derecho, se puede entender como un conjunto de obligaciones, o bien en relación con obligaciones. Sin obligaciones no podría haber pretensiones, y sin pretensiones no podría haber derechos ni derecho. Todo orden jurídico cuenta con mecanismos que garantizan que las obligaciones serán cumplidas aún en contra de la voluntad del sujeto obligado, de tal forma que si las obligaciones no se cumplen voluntariamente, debe existir la posibilidad de una aplicación forzada garantizada legalmente, y ejecutada por medios institucionales. Es precisamente en los métodos de ejecución forzosa del cumplimiento de las obligaciones en donde se encuentra la diferencia entre el derecho nacional y el DIP. El primero cuenta con procesos claros y precisos que se llevan a cabo ante instituciones estatales perfectamente organizadas - tribunales - , las que cuentan con el apoyo de la fuerza pública para hacer cumplir sus determinaciones. En cambio, el segundo cuenta con medios menos efectivos y uniformes para lograr el cumplimiento de sus obligaciones.

\section{El litigio internacional}

El primer método para lograr el cumplimiento de las obligaciones que se utiliza en el DIP es el litigio. En el litigio del DIP, las cortes carecen de la facultad coercitiva para imponer sus determinaciones, y sólo pueden servir como un medio para ejercer presión y lograr un cumplimiento voluntario.

Tres son los foros en donde se llevan los litigios internacionales: la Corte Internacional de Justicia, los tribunales creados ad hoc y los tribunales nacionales. La Corte Internacional de Justicia sólo resulta competente en aquellos casos en que las partes del litigio son Estados nacionales. En materia de la protección al medio ambiente, ${ }^{122}$ la corte ha

121 "Developments in the Law. International Enviromental Law", op. cit., nota 24, p. 1605.

122 En materia del medio ambiente, la Corte Internacional de Justicia ha resuelto el problema de 
mostrado desarrollos significativos y su jurisprudencia ha tenido un fuerte impacto sobre cómo debe ser entendido el DIP. ${ }^{123}$

En cuanto a los tribunales ad hoc que han sido establecidos para resolver diputas en materia del medio ambiente, ${ }^{124}$ se puede decir que aunque los mismos no gozan del prestigio del que goza la Corte Internacional de Justicia, sí en cambio resultan más flexibles, pues las partes deciden de común acuerdo quiénes serán los jueces, y cuáles serán las normas adjetivas y sustantivas que resultarán aplicables. ${ }^{125}$

El litigio ante los tribunales nacionales puede resultar más efectivo que los anteriores, toda vez que a ellos pueden tener acceso directamente los particulares. ${ }^{126}$

\section{Contramedidas}

Las contramedidas constituyen una de las formas pacíficas con que cuentan los sujetos del DIP para ejercer presión coercitiva con el objeto de intentar conseguir que los Estados obligados cumplan sus obligaciones internacionales. Las contramedidas pueden ser de tres tipos: represalias, contramedidas recíprocas y la retorsión. Las represalias constituyen medidas que serían ilegales de no ser por que sirven para contrarrestar un acto ilegal previo. En el DIP tradicional, las represalias normalmente incluían el uso de la fuerza, pero en la actualidad incluyen también medidas pacíficas. Las contramedidas recíprocas implican el incumplimiento de las obligaciones por parte del Estado, que a su vez a sido agraviado por el incumplimiento de las obligaciones internacionales a cargo de su contraparte; en este caso se trata de obligaciones recíprocas o directamente rela-

jurisdicción en materia de pesca entre Gran Bretaña e Islandia - ICJ Reports, 1943, p. 3-, y entre Francia e Islandia - ICJ Reports, 1974, p. 175-; el caso del Canal de Corfú —ICJ Reports, 1949, p. 22-; el caso de la disputa sobre recursos naturales entre Naru y Australia - ICJ Reports, 1989, p. 12-; el caso entre Finlandia y Dinamarca sobre el bloqueo de un pasaje marítimo por parte de ésta - ILM, vol. 31, 1992, p. 107-.

123 O'Connell, Mary Ellen, op. cit., nota 51, p. 311.

124 Destacan entre otros casos resueltos por este tipo de tribunales, el Trail Smelter Case -US v. Canada, RIAA, vol. 3, 1938 \& 1941, pp. 1905, 1962-1966; y el caso Lake Lanoux entre Francia y España - UNRIAA, vol. 12, 1957, p. 281-.

125 O'Connell, Mary Ellen, op. cit., nota 51, p. 314.

126 En Estados Unidos de América se han resuelto algunos casos por las cortes nacionales sobre el DIPMA, entre ellos destacan: Man Hing Ivory and Imports, Inc. v. Deukmejian -702 F. 2d 760 9th Cir. 1983-; Japan Whaling Assn. v. American Cetacean Soc. — 478 US 221 (1986)—; Chevron USA, Inc. v. Hammond -726 F. 2d 485 (9th Cir, 1982)—; United States and New York v. Country of Nassau —733 F. Supp. 563 (1990)—y el Amlon Metals v. FMC Corp. —775 F. Supp. 668 (1991)—. 
cionadas con la obligación incumplida. ${ }^{127}$ Finalmente, la retorsión es una contramedida que resulta consistente con las normas del DIP, pero no amigable, que el Estado ofendido aplica en contra del Estado que ha incumplido sus obligaciones del DIP; este tipo de medidas resultan independientes de la obligación quebrantada — por ejemplo, suspensión de relaciones diplomáticas o suspensión de ayuda bilateral en caso de responsabilidad internacional por violación al principio de soberanía territorial de los Estados-. ${ }^{128}$

Las contramedidas se utilizan con frecuencia y éxito en la praxis del DIP - no obstante que con frecuencia las mismas no son calificadas con su propio nombre - para responder al uso de la fuerza, para asegurar la protección de los derechos humanos y en disputas de comercio internacional. A pesar de su flexibilidad, capacidad y poder, no siempre es fácil determinar si a quien las aplica le asiste la razón legal para su uso; si ellas son proporcionales al daño causado, o si la forma como se aplican resulta la más apropiada. Asimismo, las contramedidas difícilmente pueden hacerse valer por un Estado débil que cuenta con escasos medios de presión internacional y que incluso podría resultar perjudicado con la aplicación de otra contramedida.

Las contramedidas recíprocas son las más controvertidas y probablemente las más utilizadas. Un ejemplo de éstas es la contenida en el artículo 60 de la Convención de Viena sobre Tratados, la cual prescribe que el incumplimiento material de una obligación legitima a una parte a solicitar con fundamento en el quebrantamiento la rescisión del tratado, o la suspensión de su aplicación en todo o en parte.

En el DIPMA quizá la aplicación de contramedidas recíprocas resultaría inapropiada para lograr los objetivos de un tratado, toda vez que no sería capaz de impedir que el daño ambiental continuara, e incluso, lo podría agravar. En cambio, las medidas de retorsión y las represalias parecen más apropiadas para ser aplicadas en el DIPMA, pues pueden dar lugar a sanciones que resultan mucho más efectivas, tales como suspensión

127 Este es el caso de la suspensión de concesiones autorizadas por el artículo XXIII del GATT. Según lo dispuesto por el artículo 22 del "Entendimiento relativo a las Normas y Procedimientos por los que se rige la Solución de Diferencias", las concesiones que se pongan fuera de vigor deben ser equivalentes al daño ocasionado y pertenecer al mismo sector en que se haya aplicado la medida nacional que ocasiona un daño.

128 Henkin, Louis; Pugh, Richard; Schachter, Oscar; Smith, Hans, International Law, St. Paul, Minn., 1987, pp. 541-542. 
de relaciones diplomáticas, suspensión de ayuda económica o tecnológica, o terminación de otros beneficios que se otorgan discrecionalmente. ${ }^{129}$

En el DIPMA, caracterizado por encontrarse inmerso en un proceso constante de desarrollo, no resulta fácilmente identificable el quebrantamiento de una obligación, por lo que la aplicación de contramedidas se puede dificultar, sobre todo por lo que hace a la determinación de la proporcionalidad entre el daño y la magnitud de la medida adoptada.

\section{Las negociaciones}

A partir de 1972, se muestra una práctica constante y ascendente en el sentido de admitir y reconocer como jurídicamente obligatoria la participación de los Estados en negociaciones o en consultas previas con el objeto de resolver sus conflictos medioambientales reales o potenciales. Fue así, como por ejemplo, en 1974 la Corte Internacional de Justicia solicitó de Islandia, la República Federal de Alemania y la Gran Bretaña que entraran en negociaciones para resolver sus conflictos en materia pesquera. ${ }^{130}$

Hoy la mayoría de los tratados internacionales que tienen por objeto la protección del medio ambiente prevén en su articulado la realización previa de negociaciones o consultas para el caso de que exista o pudiera existir un conflicto entre los Estados parte.

Por cuanto hace a la facultad de los Estados para solicitar la iniciación de consultas o negociaciones, cabrá preguntarse si un Estado que no resulta o pueda resultar afectado con un incumplimiento de las obligaciones medioambientales por parte de otro Estado, puede solicitar la iniciación de negociaciones. A este respecto, se puede decir que sólo en aquellos casos en que el daño o probable daño sea de tal magnitud que se pueda considerar un delito internacional, dicho tercer Estado podría solicitar la iniciación de negociaciones. ${ }^{131} \mathrm{Si}$ el derecho de solicitar y participar en negociaciones se lleva a cabo bajo el principio de verdad sabida y buena fe guardada, y los Estados se encuentran dispuestos a conducir las

129 Con base en esta idea, el Banco Mundial condiciona los préstamos a la adopción de medidas ambientales y otorga facilidades para ayudar a los Estados a cumplir sus obligaciones en la materia. Véase al respecto: Shihata, Igmar, "The World Bank and the Enviroment: A Legal Perspective", Maryland Journal of International Law \& Trade, vol. 15, 1992, p. 1.

130 Fischeries Jurisdiction case, ICJ Reports, 1974, p. 3.

131 O'Connell, Mary Ellen, op. cit., nota 51, p. 328. 
segundas con toda responsabilidad, ellas pueden servir como el principio para desarrollar un sistema de cooperación internacional en la materia. ${ }^{132}$

\section{CARACTERÍSTICAS DEL DIPMA}

Las normas internacionales que se emitieron con el objeto de proteger al medio ambiente con anterioridad al surgimiento del DIPMA como rama especial del DIP, mostraban tres características fundamentales: en principio, el hecho de que la protección internacional quedó limitada al ámbito de las relaciones de vecindad; en segundo lugar, el principio de la buena vecindad fue complementado con otros principios tales como sic utere tuo y otros tales como la prohibición de permitir conductas cuyo efecto se manifieste en daños ambientales en el territorio de otros Estados; y, por último, el principio de equitable use, según el cual el acceso de los Estados a la explotación y uso de las aguas con las que su territorio colinda o de las aguas que cruzan por su territorio, se debe dar en términos de equidad y no discriminatorios.

Lo anterior significa que dichas normas internacionales que protegían al medio ambiente —orientadas en especial por el principio de maximum use- se limitaban a la protección de intereses particulares, en especial a la protección de la salud y de los intereses económicos de los Estados. En cambio, la protección del medio ambiente en sí mismo no fue objeto de protección por tales normas. De esta forma, por ejemplo, un tratado internacional de protección de las aves, ${ }^{133}$ firmado en 1902, protegía sólo aquellas aves que resultaban útiles para la economía del campo.

Actualmente, el bien jurídicamente tutelado por las normas del DIPMA ya no son en exclusiva los elementos que lo integran, sino también su capacidad de regeneración y su posibilidad de subsistencia. Este ámbito ampliado de protección tiene por objeto garantizar a las generaciones futuras el acceso a los recursos naturales necesarios para su supervivencia, lo que implica una administración de los mismos orientada a una productividad óptima permanente, a la prevención de catástrofes y daños ecológicos, y a la cooperación en la solución de la problemática medioambiental.

El equilibrio en la relación entre, por un lado, los intereses de uso y consumo y, por el otro, los intereses de conservación del medio ambiente,

133 Reichgesetz Bundesblatt, 1906, p. 89. 
se ha organizado con base en la estructura de la institución de los derechos humanos. ${ }^{134}$ En efecto, la debida administración de los elementos que integran el medio ambiente ha llegado a ser concebida en nuestro tiempo como una condición de posibilidad de la realización de los derechos humanos tanto de las generaciones presentes como de las futuras. Aquellas no pueden disfrutar de los mismos si no cuentan con la posibilidad de usar y consumir de manera óptima los elementos del medio ambiente. Por su parte, las futuras generaciones no podrán ejercer tales prerrogativas, a menos que nuestra generación utilice y administre tales elementos de tal forma que se garantice su regeneración y el mantenimiento de su equilibrio. Así, si los derechos humanos consideran como uno de sus principios básicos el de reciprocidad, según el cuál el límite del ejercicio de los derechos es aquel que permita a los demás el ejercicio de los suyos propios, la relación de reciprocidad entre los seres humanos se debe extender en el tiempo para fijarse en una relación entre las generaciones presentes y las futuras. De esta forma, los límites jurídicos del uso y consumo de los elementos del medio ambiente de las generaciones presentes se deben establecer con base en las necesidades que las generaciones futuras tendrán para usarlos y consumirlos de la mejor manera. En este orden de ideas es como se le ha llegado a concebir al derecho a contar con un medio ambiente sano como un derecho humano de tercera generación ${ }^{135}$ que condiciona el ejercicio de otro de la misma especie: el derecho al desarrollo. Como todo derecho humano, el derecho al medio ambiente adquiere una dimensión en donde su justificación moral queda muy por encima de una justificación meramente jurídica. ${ }^{136}$

Otro elemento típico de la nueva concepción del derecho del DIPMA se relaciona con el grado de desarrollo económico de los diferentes países. Al respecto, los Estados suelen reconocer que la responsabilidad de protección ambiental es común pero diferenciada, y que las cargas necesarias para hacer frente a tal responsabilidad deben ser mayores para los países más desarrollados. De esta forma, a los países subdesarrollados se les imponen obligaciones que resulten compatibles con sus necesidades de desarrollo económico.

134 Lagoni, Rainer, op. cit., nota 1, p. 242.

135 Sobre el derecho al medio ambiente como un derecho humano de la tercera generación, véase Kunicka-Michalska, Barbara, "Derecho al medio ambiente como el derecho humano de la tercera generación”, Jurídica, núm. 22, 1993, pp. 469 y ss.

136 Véase al respecto Kiss, Alexandre y Shelton, Dina, op. cit., nota 74, p. 11. 
En el DIPMA moderno, el objeto de protección son los elementos del medio ambiente en sí mismos, independientemente del significado que tengan para los intereses concretos de las generaciones presentes.

Por otra parte, la tradicional relación de causalidad según la cual existe un Estado que provoca el daño ambiental y otro Estado víctima concretamente identificado, se ha transformado en una relación de una multitud de Estados que provocan un daño común a la naturaleza cuyos efectos alcanzan dimensiones desconocidas con anterioridad, y cuyas víctimas son también un conjunto de Estados. Con la sustitución del principio de relación formal de causalidad entre conducta atribuible a un Estado y la causación de un daño en otro Estado, por la concepción según la cual todos los Estados considerados en su conjunto son a la vez causantes del daño y víctimas del mismo, la presunción en la verificación del daño tiende a ser considerada como suficiente.

Asimismo, vale como característica de esta rama especial del DIP, la transformación de la concepción tradicional de los conceptos de vecindad y soberanía en una concepción de responsabilidad común, de cooperación regional o global, o en un criterio de common concern. ${ }^{137}$

La existencia de estos principios del DIPMA le imprime a esta rama ciertas características propias. Vale mencionar entre otras, la introducción de medidas preventivas para la protección del medio ambiente, tales como la administración de los recursos con base en criterios que permitan la protección y reproducción de los elementos de aquél y la cooperación interestatal.

Por cuanto hace al concepto tradicional de soberanía, ${ }^{138}$ bien se puede decir que el mismo se ha transformado en esta nueva rama especial del DIP para hacer posible un principio de cooperación cada vez más intensivo y extensivo. Tres aspectos son dignos de mención: en principio, se ha hecho necesaria la organización de comisiones regionales o mundiales para la administración de los recursos ambientales, cuyas resoluciones se toman con mayoría de votos y no por unanimidad. En segundo lugar, el

137 Kilian, Michael, op. cit., nota 110, p. 242.

138 Según la nueva concepción del concepto de soberanía, un Estado no puede hacer o dejar hacer lo que él quiera, sino que él tiene que considerar los posibles daños que dichas conductas puedan ocasionar fuera de sus fronteras como si los mismos se produjeran dentro de su territorio. Esto significa que los Estados se encuentran obligados a cooperar con otros Estados para prevenir los daños al medio ambiente, y posiblemente también a renunciar a la explotación de recursos que se encuentren ubicados dentro de sus territorio. Esta nueva concepción encuentra su expresión en los principios de: shared resources, common heritage/concern, orde public y jus cogens. 
desarrollo del principio de solidaridad en materia ambiental que ha surgido con base en la toma de conciencia de que las diferentes problemáticas ambientales nacionales se encuentran en una relación de interdependencia internacional y que los daños ambientales en un país pueden repercutir en el equilibrio ecológico regional o mundial. Este principio obliga a los Estados a cooperar para combatir y prevenir de manera conjunta los daños ambientales mediante el intercambio de información permanente y a través de mecanismos para llevar cabo consultas y negociaciones.

Otra característica de especial importancia que distingue al DIPMA es que quizá en esta rama especial, como en ninguna otra, se ha presentado una transformación del DIP que ha significado el abandono de un simple derecho de coexistencia para transformarse en un derecho de cooperación. ${ }^{139}$ Las normas tradicionales del DIP se caracterizan por establecer límites al ejercicio de las potestades soberanas - derecho de coexistencia-, exigiendo de los Estados básicamente obligaciones de no hacer. Esto debido a que su objetivo es el establecimiento de estándares y mecanismos para evitar colisiones en las relaciones interestatales. Por su parte, las normas modernas del DIP precisan obligaciones de hacer que fijan las bases para un trabajo común de los Estados, tarea ésta a la que contribuye una participación cada vez más decidida de las organizaciones internacionales — derecho de cooperación- ${ }^{140}$ Como obligaciones propias del derecho de cooperación en el DIPMA encontramos entre otras: el intercambio de información; ${ }^{141}$ la advertencia en casos de peligro de daños transfronterizos; la participación en consultas o negociaciones; y de manera muy especial la formación de organismos internacionales. ${ }^{142}$

139 Una de las características más importantes que marcó la evolución del DIP en el siglo XX, fue la transformación de un simple derecho de coexistencia en un derecho de cooperación. El rasgo fundamental de este DIP de cooperación consiste en la creación de instrumentos e instituciones para la búsqueda de soluciones y la prevención de problemas internacionales por la vía del trabajo conjunto y de la ayuda mutua. Al respecto véase Verdross, Alfred y Simma, Bruno, Universelles Völkerercht, Berlín, Duncker \& Humblodt, 1976, p. 41; y Rojas, Víctor, op. cit., nota 34, p. 264.

140 Verdross, Alfred y Simma, Bruno, Universelles Völkerercht, Berlín, Duncker \& Humblodt, 1976, pp. 59 y 60; y Stocker, Werner, Das Prinzip des Common Heritage of Mankind als Ausdruck des Staatengemeinscahtsinteressen im Völkerrecht, Zürich, Schultess Polygraphische Verlag, 1993, p. 219.

141 En cuanto a la obligación de intercambio de información, la misma se cumple de diferentes formas: ya sea mediante el intercambio permanente de información; mediante el acceso a la información general que se encuentre en poder de un Estado; o el otorgamiento de información previa sobre las actividades que se tenga planeado realizar en el futuro y que puedan tener un impacto sobre el medio ambiente con efectos transnacionales.

142 Ipsen, Knut, op. cit., nota 3, p. 861. 
La razón por la que en el DIPMA el derecho de cooperación se ha desarrollado de manera especial, se debe a que, la problemática ambiental se encuentra asociada a otro tipo factores preponderantemente de tipo económico - tales como desventajas en el sistema de competencia internacional, debido a la diferencia de estándares de producción que existen de un país a otro- o social - tales como el desempleo que se puede generar mediante políticas protectoras del ambiente, o la explosión demográfica-, ${ }^{143}$ lo que exige un trabajo conjunto tanto a nivel técnico como político más intenso por parte de las partes involucradas.

Por lo que hace al coeficiente de efectividad de las normas de la rama especial del DIP que nos ocupa, se puede decir que el mismo muestra un déficit, que en mayor o menor medida refleja la mayor importancia que se le concede a otros factores tales como el crecimiento económico, el empleo, la balanza comercial, el ahorro, etcétera. Otro aspecto no menos importante en esta problemática es el hecho de que en muchos órdenes jurídicos nacionales, la protección del medio ambiente, o bien carece de significado, o no ha llegado a adquirir la importancia que en realidad merece. En efecto, la praxis jurídica del DIPMA muestra que la puesta en marcha con éxito de un tratado internacional, en gran medida depende de una infraestructura tanto de carácter jurídico como administrativo de los Estados parte, así como de la conciencia ambiental que tengan sus ciudadanos. ${ }^{144}$

\section{CONCLUSIONES}

1. El DIPMA es una rama especial del DIP que se ha desarrollado ha partir de la década de los sesenta y principios de la década de los setenta del siglo XX, que comprende las normas internacionales cuyo objeto es la protección del medio ambiente, y que se comprenden tanto en regulaciones especiales como en otras de naturaleza muy diversa.

2. Hasta principios de los setenta del siglo XX, la protección ambiental con ayuda de los instrumentos del DIP se limitó a la defensa de determinados elementos del medio ambiente, principalmente de las aguas, y su motivación fundamental fueron las necesidades de explotación de los recursos naturales.

144 Ipsen, Knut, op. cit., nota 3, p. 869. 
3. El punto de partida del DIPMA propiamente dicho comienza con la Conferencia de Naciones Unidas de Estocolmo que se celebró entre el 5 y el 16 de junio de 1972. Debido al éxito que alcanzo la conferencia, en diciembre de 1972 se emitió el PNUMA.

4. En los veinte años que mediaron entre las conferencias de Estocolmo y la de Río, se concluyó una gran multitud de tratados sobre materias que anteriormente no se encontraban reguladas, tales como la protección de la capa de ozono y la contaminación transfronteriza del aire. Asimismo, se signaron múltiples y diversos instrumentos de soft law cuyo objeto fue la protección del entorno natural.

5. El gran desarrollo a nivel jurídico-internacional, por cuanto hace a la introducción de mecanismos de carácter preventivo y a las obligaciones de cooperación que caracterizó a la etapa anterior a la Conferencia de Río, contrasta con los grandes desastres ambientales de Amoco Cádiz, Exxon Valdez, Soveso, Bophal, Tschernobyl y Basilea.

6. La Conferencia de Río que tuvo verificativo entre el 3 y el 14 de junio de 1992, y que fue la más grande que jamás haya organizado la ONU, tuvo como resultado cinco documentos fundamentales: la Declaración de Río de Janeiro; los Principios Generales de la Conservación de los Bosques; la Agenda 21; la Convención sobre Cambio Climático y el Convenio sobre la Diversidad Biológica. Además, en la misma adquirió reconocimiento pleno el concepto de desarrollo sustentable. En el aspecto institucional la Conferencia llevó a la creación de la Comisión de Desarrollo Sustentable en el marco de la ONU.

7. Las fuentes del DIPMA son las mismas que se encuentran enumeradas en el artículo 38 del Estatuto de la Corte Internacional de Justicia. Como fuente de segundo orden, algunos autores reconocen como normas del DIPMA las contenidas en los instrumentos de soft law, y aquellas que aún cuando provienen del derecho nacional del medio ambiente se aplican con efectos extraterritoriales.

8. Los tratados son el instrumento que de manera más importante ha contribuido al desarrollo del DIPMA. Hoy éstos regulan materias tales como el comercio de especies en peligro de extinción; la contaminación del aire; el transporte de materiales peligrosos; la contaminación de los océanos; la contaminación ocasionada por barcos; la contaminación del medio ambiente marino; la contaminación de los ríos y aguas interiores; el medio ambiente del Antártico; la biodiversidad; el cambio de clima, etcétera. 
9. El método de conclusión de acuerdos internacionales mediante convenios seguidos de protocolos especiales ha resultado efectivo para conminar a los Estados a adquirir obligaciones de DIPMA. Esto se debe a que dicho sistema da lugar a varias rondas de negociaciones que dosifican la aceptación de cargas contractuales y que permiten una adaptación más efectiva de las obligaciones internacionales a las nuevas evidencias científicas. Sin embargo, este recurso puede implicar mucho tiempo desde el momento de que se concluya el tratado hasta que los Estados tengan que cumplir obligaciones concretas.

10. A pesar del gran número de tratados internacionales en materia ambiental que se han celebrado durante las últimas tres décadas, su aplicación resulta problemática debido a que normalmente carecen de mecanismos eficientes para el aseguramiento de sus normas. Asimismo, algunos de ellos cuentan con cláusulas de escape y carecen de mecanismos de financiamiento de las tareas a ser realizadas por los Estados.

11. Las normas de costumbre internacional han aportado muy poco al desarrollo del DIPMA moderno. Entre éstas encontramos tres tipos de normas: las materiales, las procesales y las relativas a la responsabilidad civil.

12. Entre las normas de costumbre material del DIPMA encontramos el principio según el cual a los Estados no les es permitido llevar a cabo conductas, o permitir que en el territorio donde ejercen su poder soberano se lleven a cabo conductas que tengan por resultado un daño significativo al medio ambiente del territorio, espacio, o aguas que se localizan fuera de sus fronteras; la que exige una repartición y acceso equitativo a los recursos naturales comunes a varios Estados — principle of equitable apportionment/utilization - , y en algunas regiones del mundo, la obligación de adoptar medidas preventivas — precautionary measures - para evitar daños medioambientales transfronterizos y la obligación de proporcionar información relevante cuando un Estado que se encuentre en posibilidad de ser afectado en su medio ambiente por conductas de otro, requiera la misma para tomar medidas preventivas.

13. Como normas procesales consuetudinarias del DIPMA se suelen señalar: la obligación que tienen los Estados de informar a las posibles víctimas sobre los daños que por sus conductas, incluidas las actividades que en el futuro se tenga pensado llevar a cabo, se hayan ocasionado o puedan ocasionar en el territorio de otros Estados y la obligación de participar en consultas con el propósito de negociar soluciones cuando el Esta- 
do que resulta, o puede resultar perjudicado por los problemas ambientales, lo solicita del Estado que ocasiona o puede ocasionar el daño.

14. Las normas consuetudinarias relativas a la responsabilidad civil por daños medioambientales aún no son plenamente aceptadas por todos los Estados. Una obligación a responder por daños medioambientales existe de dos formas: por una parte, en cuanto a los daños que se ocasionen sobre personas privadas o sus bienes; $y$, por la otra, por lo que hace a los daños que se ocasionen en bienes patrimoniales de un Estado.

15. En el derecho de costumbre del DIPMA se advierte una tendencia a privilegiar a las costumbres que impliquen una forma preventiva de cooperación ambiental sobre las costumbres tradicionales que se derivan del principio de buena vecindad.

16. Como principios generales del derecho que resultan aplicables al DIPMA encontramos: el principio de la verdad sabida y buena fe guardada; el principio de buena vecindad; la prohibición del mal uso del derecho; el principio de solidaridad de los Estados, y el principio de la herencia común de la humanidad. Algunos autores también incluyen dentro de los principios generales del DIPMA a los principios de prevención, $\mathrm{y}$ aquél que sostiene que el que contamina paga; sin embargo, a este respecto, la doctrina se muestra aún escéptica.

17. Las normas del soft law resultan particularmente atractivas para el DIPMA, pues suelen servir como el primer paso en la creación de un ambiente que pueda contribuir a la conclusión de instrumentos de hard law que establezcan normas obligatorias a cargo de los Estados.

18. El tema de la protección del medio ambiente ha llegado a ser un objetivo habitual de los OI. Las tareas que llevan a cabo los OI en esta materia consisten en la preparación de la información, foros y demás elementos necesarios que servirán de base para la creación de las normas del DIPMA del futuro; en la asistencia y control en el cumplimiento de las obligaciones internacionales; y en la administración de los mecanismos de solución de diferencias.

19. En la aplicación de las normas del DIPMA destaca el litigio internacional que se ha llevado ante la Corte Internacional de Justicia. Por otra parte, la aplicación de contramedidas recíprocas en el DIPMA resultaría inapropiada, pues no sería capaz de impedir que el daño ambiental continuara, por lo que resultan más adecuadas la retorsión y las represalias. También las negociaciones resultan un medio efectivo para prevenir daños ambientales o solucionar problemas en la materia. 
20. Como característica fundamental del DIPMA moderno destaca el hecho de que el bien jurídicamente tutelado por sus normas es el medio ambiente y sus capacidad de regeneración. Asimismo, en la concepción moderna del DIPMA la protección del medio ambiente se considera con el rango de un derecho humano. Por otra parte, destaca el principio de responsabilidad común pero diferenciada y la introducción de mecanismos preventivos. De igual forma, digno de mención es que en el DIPMA la transformación del DIP de coexistencia en un DIP de cooperación ha mostrado un desarrollo más profundo que en otras ramas. Sin embargo, todavía la aplicación de las normas del DIPMA no es la óptima, lo que en mayor o menor medida se debe a que existen prioridades nacionales e internacionales — tales como el crecimiento económico, el empleo, el ahorro, etcétera- a las que se les concede mayor jerarquía que a la protección medioambiental. 